\title{
CIHR excludes Aboriginal health in review
}

$\mathrm{T}$ he leaders of Canada's largest medical research funding organization did not consider the ramifications of proposed restructuring on Aboriginal health research, recently released documents suggest.

The Canadian Institutes of Health Research (CIHR) convened two working groups - one internal, the other external - in 2014 to examine its effectiveness. Despite glaring inequities in the health of Aboriginal Canadians, neither group's final report evaluates the effect of recommended changes on the Institute of Aboriginal Peoples' Health.

"When it comes to the Aboriginal experience, I don't think the senior [leadership] levels nor the governing council have a good grasp of Aboriginal realities," says Frederic Wien, principal investigator of the Atlantic Aboriginal Health Research Program.

"They have taken a number of system-wide decisions and they haven't paid any attention to how those system-wide decisions affect different constituencies, especially the Aboriginal constituency."

Wien is the co-chair of the Aboriginal Health Research Steering Committee, which Aboriginal researchers formed this summer to oppose what they describe as "the crisis that exists between the [CIHR] and the Aboriginal health community."

CIHR released the two working group reports on Dec. 9, in response to a request from CMAJ. The Aboriginal Committee had been unable to get the external working group report.

CIHR declined CMAJ's requests for an interview with Dr. Alain Beaudet, its president, or a vice-president.

The word "Aboriginal" does not appear in the external working group's report. According to the list in the report, the group did not consult any Aboriginal health organizations or prominent Aboriginal health researchers during its work.

The Institute of Aboriginal Peoples' Health and its central role in ensuring continued improvements in health out-

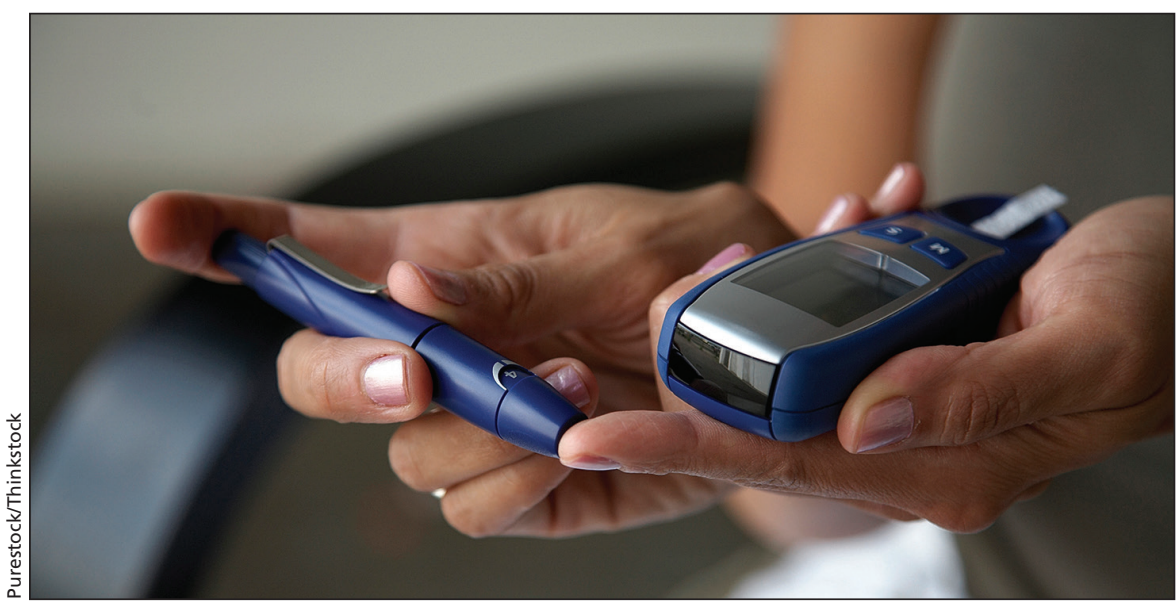

Aboriginal people have a seven-year gap in life expectancy compared to other Canadians, as well as significantly higher rates of diabetes and other chronic diseases.

comes and reducing health inequities is mentioned only in an appendix to the internal working group's report.

CIHR is proposing numerous changes to its governing structure, including a new requirement for many grant recipients to find matching funds. That requirement is particularly problematic for Aboriginal health research projects, which typically address health disparity and are not geared to generating profit a prime motivation for many private-sector funding sources, says Dr. Laura Arbour, a professor in the Department of Medical Genetics at the University of British Columbia, Vancouver.

For example, Arbour investigates the causes and predisposition to sudden arrhythmic death from Long QT syndrome in a First Nations' population in Northern BC, which she says would be unlikely to interest industry because it is such a small and specific population.

Much of the motivation for the CIHR changes appears to be cost-cutting, Arbour told $C M A J$ in an interview.

"The problem is that ... it's shortterm cost-saving, which in the long run is going to cost our system so much more," she says.

Other proposed CIHR changes that the steering committee says will disproportionately affect Aboriginal health research and health outcomes include:
- cuts to funding for the Network Environments for Aboriginal Health Research, which built capacity by funding students, most of them Aboriginal

- designating half of CIHR's open competition research funding for established and "star" scholars, which will put Aboriginal researchers who are less established at a disadvantage

- cutting half the budget of the Institute of Aboriginal Peoples' Health (along with all the other institutes) and placing the other $50 \%$ of funds in a common research pool

- eliminating 9 of the 13 institute advisory boards, including the board for the Institute of Aboriginal Peoples' Health

- reassigning some of the Ottawabased staff of the Institute to more general duties, not specific to the Aboriginal institute.

"We feel kind of betrayed by CIHR," says Rod McCormick, a Mohawk researcher and professor who holds the BC Regional Innovation Chair in Aboriginal Early Childhood Development at Thompson Rivers University in Kamloops, BC. "Without any explanation, they're just getting rid of everything we've built up over the past 14 years [since CIHR was established]."

The Aboriginal Health Research 
Steering Committee, which McCormick co-chairs, fears CIHR will dismantle the Institute of Aboriginal Peoples' Health altogether, although the external working group report notes its members "do not have sufficient knowledge to judge whether any Institute should be dismantled or merged."

The committee's request for a consultation before CHIR implements any changes has not yet been granted. In a Dec. 9 letter to Wien, Beaudet confirmed many of the changes but said two vicepresidents and the scientific director of the Institute of Aboriginal Peoples' Health will "reach out to the community to establish meaningful dialogue" and strengthen Aboriginal health-research capacity.

Several First Nations researchers are particularly concerned about the effect of cutting funding for students.

"Our prospects for continuing the journey to culturally appropriate research equity is wiped away," Dr. Judith Bartlett, a Métis associate professor at the University of Manitoba, wrote in an open letter to Beaudet Nov. 18. - Laura Eggertson, Ottawa, Ont.

CMAJ 2015. DOI:10.1503/cmaj.109-4965

\section{Bruce Squires Award for microbiome study}

$\mathrm{T}$ he authors of a study looking at the variability of gut flora in healthy infants with different diet and delivery methods have been awarded for their contribution to health care research in Canada.

Dr. Meghan Azad and coauthors are the recipients of the Bruce Squires Award for their article "Gut microbiota of healthy Canadian infants: profiles by mode of delivery and infant diet at 4 months" (CMAJ 2013;185:385-94). It was one of the most highly cited CMAJ articles in 2014 and had significant downloads.

The Bruce Squires Award is presented annually to the authors of a research article that promotes high standards of reporting and evidence-based medicine. The award honours the late Dr. Bruce Squires who was CMAJ's editor-in-chief from 1989-1996.

"The Bruce Squires Award is given for research that is likely to have a high impact on patient care, so we like to choose research that is either at the beginning of a research story or at the end of a research story," said CMAJ Editor-inChief Dr. John Fletcher. "In previous years we have awarded systematic reviews giving the definitive result at the end of a story of research. This year's winner is a break with tradition in that it is at the beginning of the story of the microbiome and how our gut flora interacts with our immune system and produces disease." Fletcher said he has high hopes for this area of research in the future.

"Gut microbes clearly play an important role in human health and disease, but microbiome research is a relatively new field, and most studies have been conducted in adults," said Azad. The CMAJ

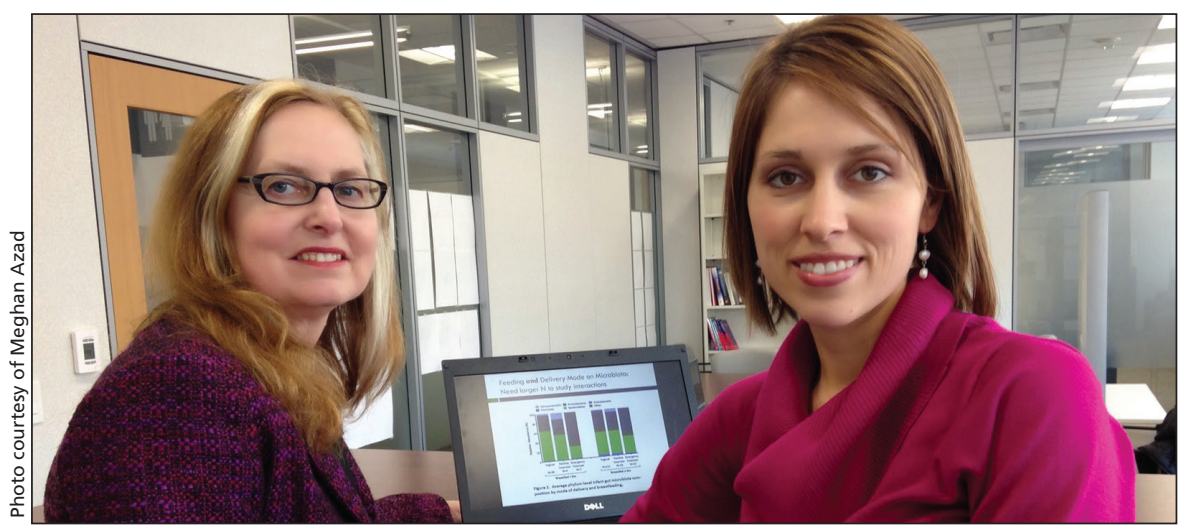

Dr. Anita Kozyrskyj (left) and Dr. Meghan Azad are members of the research team that received the Bruce Squires Award for their study on the gut microbiome of infants.

study examined the microbiome of 24 infants who were recruited as part of the Canadian Healthy Infant Longitudinal Development (CHILD) cohort, which was conducted at four sites. Researchers studied the changes in gut flora based on delivery mode, use of maternal antibiotics, group B streptococcus status and diet. The authors found that infant gut flora varied by delivery and breastfeeding status. Bacteroides was underrepresented in infants born through cesarean delivery when compared to infants delivered vaginally. In addition, the diversity of gut microbiota in breastfed infants was lower than that of formula-fed infants. These findings are consistent with those in previous studies in Europe, but used new DNA sequencing technology to identify a greater diversity of gut flora.

Azad, an assistant professor of Pediatrics and Child Health at the University of Manitoba in Winnipeg, completed her postdoctoral fellowship in pediatrics at the University of Alberta in Edmonton. Her research focuses on the gut microbiome and the early-life origins of chronic disease. She coauthored the paper with the primary investigators of the Synergy in Microbiota team: Dr. Anita Kozyrskyj, professor of pediatrics at the University of Alberta and Dr. James Scott, associate professor, Dalla Lana School of Public Health, University of Toronto.

"My team and I are absolutely delighted to receive the award for our research which represents the first microbiome study of North American infants," said Kozyrskyj. "We intentionally selected $C M A J$ because of our interest in evaluating early life interventions such as cesarean section delivery and antibiotic treatment as being very relevant to obstetricians, pediatricians and of course parents."

The team is expanding the study to include more infants and long-term follow up. Infant feeding and birth practices are complex decisions for parents. The research identifies gut microbiota as a new factor to consider in this process, said Kozyrskyj. — Moneeza Walji, CMAJ

CMAJ 2015. DOI:10.1503/cmaj.109-4970 